\title{
Timosaponin A-III reverses multi-drug resistance in human chronic myelogenous leukemia K562/ADM cells via downregulation of MDR1 and MRP1 expression by inhibiting PI3K/Akt signaling pathway
}

\author{
JIE-RU CHEN $^{1 *}$, XIU-HONG JIA ${ }^{1 *}$, HONG WANG $^{1}$, YING-JIE YI $^{1}$, JIAN-YONG WANG $^{1}$ and YOU-JIE LI ${ }^{2}$ \\ ${ }^{1}$ Department of Pediatrics, The Affiliated Hospital of Binzhou Medical University, Binzhou, Shandong 256603; \\ ${ }^{2}$ Department of Biochemistry and Molecular Biology, Key Laboratory of Tumour Molecular Biology, \\ Binzhou Medical University, Yantai, Shandong 264003, P.R. China
}

Received January 7, 2016; Accepted February 14, 2016

DOI: $10.3892 /$ ijo.2016.3423

\begin{abstract}
One of the major causes of failure in chemotherapy for patients with human chronic myelogenous leukemia (CML) is the acquisition of multidrug resistance (MDR). MDR is often associated with the overexpression of drug efflux transporters of the ATP-binding cassette (ABC) protein family. Timosaponin A-III (TAIII), a saponin isolated from the rhizome of Anemarrhena asphodeloides, has previously demonstrated the ability to suppress certain human tumor processes and the potential to be developed as an anticancer agent. Nevertheless, the ability of TAIII to reverse MDR has not yet been explored. In this study, the adriamycin (ADM) resistance reversal effect of TAIII in human CML K562/ADM cells and the underlying mechanism was investigated. The Cell Counting Kit-8 (CCK-8) assay showed that TAIII had a reversal effect on the drug resistance of K562/ADM cells. Flow cytometry assay showed increased intracellular accumulation of ADM after cells were pretreated with TAIII, and the changes in the accumulation of rhodamine-123 (Rho-123) and 5(6)-carboxyfluorescein diacetate (CFDA) dye in K562/ADM cells were determined to be similar to the changes of intracellular accumulation of ADM. After pretreatment of cells with TAIII, the decreasing expression of P-gp and MRP1 mRNA was examined by reverse transcription polymerase chain reaction (RT-PCR). Western blotting showed TAIII inhibiting P-gp and MRP1 expression depended on the PI3K/Akt signaling
\end{abstract}

Correspondence to: Professor Xiu-Hong Jia, Department of Pediatrics, The Affiliated Hospital of Binzhou Medical University, Binzhou, Shandong 256603, P.R. China

E-mail: jiaxiuhong001@163.com

${ }^{*}$ Contributed equally

Key words: timosaponin A-III, multidrug resistance, reverse, P-gp, MRP1, PI3K/Akt signaling pathway pathway by decreasing the activity of p-Akt. Moreover, wortmannin an inhibitor of PI3K/Akt signaling pathway has a strong inhibitory effect on the expression of p-Akt, P-gp and MRP1. Besides, the combined treatment with TAIII did not have an affect on wortmannin downregulation of p-Akt, P-gp and MRP1. Taken together, our findings demonstrate, for the first time, that TAIII induced MDR reversal through inhibition of P-gp and MRP1 expression and function with regained adriamycin sensitivity which might mainly correlate to the regulation of PI3K/Akt signaling pathway.

\section{Introduction}

Chronic myeloid leukemia (CML) is a well-described hematopoietic malignancy as a result of the generation of the BCR-ABL fusion oncogene (1). Systemic chemotherapy is the main treatment method for patients with CML. Although the majority of the CML patients respond to therapy, $>62.5 \%$ of the patients will experience multidrug resistance (MDR) (2). MDR is the main reason for tumor chemotherapeutic failure, and finding selective MDR reversal agents has become a research focus. MDR is often associated with overexpression of drug efflux transporters belonging to adenosine triphosphate (ATP)-dependent binding cassette (ABC) protein family (3). A large number of studies revealed that multidrug resistance 1 (MDR1), also known as P-glycoprotein or ABCB1, and multidrug resistance-associated protein 1 (MRP1), also known as $\mathrm{ABCC} 1$, which are ABC transporters and work as drug efflux pumps, play crucial roles in MDR of human CML (2-7).

The phosphoinositide 3-kinase/serine-threonine kinase (PI3K/Akt) signaling pathway is a well-known fundamental intracellular signaling transduction pathway involved in multiple biological processes both in normal and cancer cells, including gene transcription and translation, cell growth, proliferation and survival, cell metabolism, cell cycle progression, apoptosis and autophagy (8-10). Besides, there is an increasing amount of preclinical data supporting that the PI3K/Akt signaling pathway is also involved in the drug resistance of different types of human malignant cells, including 
CML (2,4,5,12-15). A previous study demonstrated that the resistant CML cell line K562/ADM presented higher PI3K/ Akt activity than the sensitive one and was in accordance with the MDR phenotype (2). Moreover, there is a positive relationship between the levels of P-gp and MRP1 and the activity of PI3K/Akt signaling pathway (4). The increasing level of p-Akt showed high activation of PI3K/Akt signaling pathway in drug-resistant CML cell lines. Blocking the PI3K/Akt signaling pathway with LY294002 (a PI3K-specific inhibitor) or Akt siRNA could downregulate the expression of P-gp and MRP1 and restore drug sensitivity $(2,4)$. Although the exact mechanisms that underlie the role of PI3K/Akt signaling pathway activation remain unclear, these data clearly support that PI3K/Akt pathway plays an important role in the pathogenesis of MDR in CML.

Rhizoma Anemarrhenae (Zhimu in Chinese), a wellknown traditional Chinese medicinal herb, which is officially listed in the Chinese Pharmacopoeia, has been effectively used for febrile diseases in oriental clinical practices. Timosaponin A-III (TAIII), a steroidal saponin isolated from the rhizomes of Anemarrhena asphodeloides (AA), has been credited with a wide spectrum of bioactivities, including improving learning and memory (16), inhibiting inflammation (17), suppressing allergic reaction (18), controlling hyperglycemic (19,20), activating autophagy (21) and inducing cancer cells apoptosis (22-24). However, the ability of TAIII to reverse MDR has not been reported. In this study, for the first time, we explored the effects of TAIII on the reversal of multidrug resistant and demonstrated its molecular mechanism.

\section{Materials and methods}

Chemicals and reagents. TAIII (purity $>98 \%$, Yuanye Bio-Technology Co. Ltd., Shanghai, China), wortmannin (a specific PI3K inhibitor, Beyotime Institute of Biotechnology, Shanghai, China), rhodamine-123 (Rho-123, Sigma Chemical Co., St. Louis, MO, USA) and 5(6)-carboxyfluorescein diacetate (CFDA, Sigma Chemical Co.) were dissolved in dimethyl sulfoxide (DMSO, Amresco, USA) at the concentrations $200 \mu \mathrm{M}, 10 \mathrm{mM}, 1 \mathrm{mg} / \mathrm{ml}$ and $1 \mathrm{mM}$ respectively aliquoted and stored at $-20^{\circ} \mathrm{C}$. The stock solutions of TAIII contained a final DMSO concentration of $<0.1 \%$. Adriamycin (ADM) purchased from Melone Pharmaceutical Co., Ltd. (Dalian, China) was dissolved in a concentration of $2 \mathrm{~g} / \mathrm{l}$ with $\mathrm{ddH}_{2} \mathrm{O}$ and stored at $-20^{\circ} \mathrm{C}$. Rabbit polyclonal antibodies including anti-MDR1, MRP1, total-Akt and phosphor-Akt (Ser473) were purchased from Beijing Bioss Bio-Technology Co., Ltd. (Beijing, China). Rabbit polyclonal antibodies against GADPH was obtained from Goodhere Biotechnology Co., Ltd. (Hangzhou, China).

Cell lines and cell culture. The human CML K562 cells were obtained from Key Laboratory of Tumour Molecular Biology of Binzhou Medical University (Binzhou, China) and its MDR subline K562/ADM was purchased from the Department of Pharmacology, the Institute of Hematology of Chinese Academy of Medical Sciences (Tianjin, China). The cells were maintained in RPMI-1640 medium supplemented with $10 \%$ fetal bovine serum (FBS, both from Hyclone, USA), $100 \mathrm{U} / \mathrm{ml}$ of penicillin and $0.1 \mathrm{mg} / \mathrm{ml}$ streptomycin at $37^{\circ} \mathrm{C}$ in a humidified atmosphere containing $5 \% \mathrm{CO}_{2}$. K562/ADM cells were cultured in the same medium with an additional $4 \mathrm{mg} / \mathrm{l}$ ADM. Before the experiment, K562/ADM cells were cultured in drug-free medium for $72 \mathrm{~h}$.

Multidrug resistance determination in K562/ADM cells. Cell Counting Kit-8 (CCK-8; Dojindo Molecular Technologies, Inc., Shanghai, China) was used to determine the survival rate of cells incubated with ADM. The cells were seeded in a 96-well plate at a density of $5 \times 10^{3}$ cells/well in RPMI-1640 containing $10 \% \mathrm{FBS}$. Then, various concentrations of ADM (0.2-1.6 mg/l for K562 cells and 16-128 mg/l for K562/ADM cells) were added. After the cells were incubated at $37^{\circ} \mathrm{C}$ in $5 \% \mathrm{CO}_{2}$ for $24 \mathrm{~h}, 10 \mu \mathrm{l}$ of CCK-8 solution was added to each well and incubated for an additional $4 \mathrm{~h}$. The absorbance was measured at $570 \mathrm{~nm}$ with a fluorescence spectrofluorometer (F-7000; Hitachi HighTechnologies Corp., Tokyo, Japan). A blank well containing only medium and drugs was used as a control. The $50 \%$ inhibition of cell growth $\left(\mathrm{IC}_{50}\right)$ produced by ADM was calculated.

TAIII intrinsic cytotoxic activity determination in K562/ ADM cells. CCK-8 assay was also used to determine the direct cytotoxic activity of TAIII as described above. TAIII of different concentrations at 1-16 $\mu \mathrm{M}$ were added to each well for $24 \mathrm{~h}$. Relative survival rate $(\%)$ of each group = absorbance of the experimental group/the absorbance of the control group $\mathrm{x} 100 \%$. The calculated TAIII concentration at $90 \%$ survival rate was IC10. The concentrations below IC10 were selected as the experimental concentration for TAIII to reverse drug-resistance.

Reversal efficacy of TAIII determination. Briefly, the K562/ ADM cells were seeded into a 96-well plate, then 1 or $2 \mu \mathrm{M}$ TAIII with or without various concentrations of ADM (4-32 $\mu \mathrm{g} / \mathrm{ml}$ ) was added to each well accordingly. Then, the quantity of viable cells were determined by CCK- 8 assay according to the manufacturer's instructions. ADM IC $\mathrm{I}_{50}$ was calculated using the untreated cells as the $100 \%$ viable control. The reversal fold (RF) values, as potency of reversal, were obtained from the following formula: $\mathrm{RF}=\mathrm{IC}_{50}$ of $\mathrm{ADM}$ only/ $\mathrm{IC}_{50}$ of $\mathrm{ADM}$ with TAIII.

Cellular uptake of ADM. K562/ADM cells were plated in 6 -well plates at a concentration of $1 \times 10^{6}$ cells in $1 \mathrm{ml}$ growth medium. After incubation alone or with TAIII (1 and $2 \mu \mathrm{M})$ at $37^{\circ} \mathrm{C}$ for $24 \mathrm{~h}, 3 \mathrm{mg} / \mathrm{ADM}$ was added to designated $\mathrm{K} 562 / \mathrm{ADM}$ cells for another $1 \mathrm{~h}$ at $37^{\circ} \mathrm{C}$. Then, the cells were harvested by centrifugation and washed twice with ice-cold phosphate-buffered saline (PBS). The cell-associated mean fluorescence intensity (MFI) of ADM was detected by flow cytometer using a FACSCalibur (Beckman Coulter, Brea, CA, USA) with excitation/emission wavelengths of 485/580 nm.

Rho-123 and CFDA accumulation assay. Rhodamine-123 (Rho-123) and 5(6)-carboxyfluorescein diacetate (CFDA) were, respectively, used to evaluate the transport function of P-gp and MRP1 in K562/ADM cells by flow cytometric analysis. Rho-123 was a special substrate for P-gp which contains yellow-green fluorophores. CFDA was used as a model MRP1 substrate to evaluate the function of MRP1 (25). 
Table I. Determination of multidrug resistance according to the sensitivity of K562/ADM and K562 cells toward ADM (means $\pm \mathrm{SD}$ of triplicate experiments).

\begin{tabular}{lccc}
\hline Treament & $\begin{array}{c}\mathrm{K} 562 / \mathrm{ADM} \\
\mathrm{IC}_{50}(\mu \mathrm{g} / \mathrm{ml})\end{array}$ & $\begin{array}{c}\mathrm{K} 562 \\
\mathrm{IC}_{50}(\mu \mathrm{g} / \mathrm{ml})\end{array}$ & Resistant fold \\
\hline ADM & $32.176 \pm 3.1718^{\mathrm{a}}$ & $1.013 \pm 0.1008$ & 31.7784 \\
\hline
\end{tabular}

${ }^{\mathrm{a}} \mathrm{P}<0.05$ vs. K562 cells.

A total of $6 \times 10^{5}$ cells were seeded into 6 -well plates which were pretreated with TAIII ( 1 and $2 \mu \mathrm{M})$ for $24 \mathrm{~h}$ followed by combined-treatment with Rho-123 $(2 \mu \mathrm{g} / \mathrm{ml})$ or CFDA $(1 \mu \mathrm{M})$ for another $30 \mathrm{~min}$ at $37^{\circ} \mathrm{C}$ in $5 \% \mathrm{CO}_{2}$. Cells with the equivalent amount of DMSO, without Rho-123, CFDA and TAIII were used to evaluate cell auto-fluorescence. Then, the cells were harvested and washed twice with cold PBS and subsequently analyzed by flow cytometry. The values were expressed by the mean fluorescence intensity of Rho-123 and CFDA.

$R T-P C R$ analysis. After treatment with 1 or $2 \mu \mathrm{M}$ TAIII for $24 \mathrm{~h}, \sim 3 \times 10^{6}$ cells were harvested for RT-PCR analysis. Total RNA was isolated from the cells using TRIzol reagent (Invitrogen, USA) according to the manufacturer's instructions. Total RNA was reverse transcribed to cDNA and stored at $-20^{\circ} \mathrm{C}$. Primers were synthesized by Sangon Biotech Co., Ltd. (Shanghai, China). Primers used in RT-PCR were as follows: MDR1 forward, 5'-GGAGCCTACTTGGTGGCACATAA-3'; reverse, 5'-TGGCATAGTCAGGAGCAAATGAAC-3'. MRP1 forward, 5'-CTGGGAACATGATTAGGAAGC-3'; reverse, 5'-GAGGATTTCCCAGAGCCGAC-3'. GAPDH forward, 5'-GAAGGTGAAGGTCGGAGTC-3'; reverse, 5'-GAAGAT GGTGATGGGATTTC-3'. RT-PCR was performed on an ABI PRISM 7500 real-time PCR system (Applied Biosystems, Foster City, CA, USA) by using SYBR Green reaction kit (Takara, Bio, Otsu, Shiga, Japan). The reaction system of PCR was: SYBR green reagent, forward primer, reverse primer, template cDNA and nuclease-free distilled water. PCR programs were carried out as follows: $95^{\circ} \mathrm{C}$ for $30 \mathrm{sec}$, followed by 45 cycles of $95^{\circ} \mathrm{C}$ for $5 \mathrm{sec}, 60^{\circ} \mathrm{C}$ for $30 \mathrm{sec}$. GAPDH served as an internal control. The PCR products were separated by $1 \%$ agarose gels. The gels were scanned and analyzed by the Gel Imaging System. RT-PCR for each gene of each cDNA sample was assayed in triplicate.

Western blot analysis. After different treatments, the cells were harvested and washed with PBS. Lysis buffer $(100 \mu \mathrm{l})$ (Beyotime Biotechnology) was added and the protein concentration of the lysate was determined using a Bicinchoninic Acid Protein Assay kit (Beyotime Biotechnology). The lysed samples containing $50 \mu \mathrm{g}$ were separated by $6-10 \%$ sodium dodecyl sulphate polyacrylamide gel electrophoresis (SDS-PAGE, Beyotime Biotechnology) with a constant voltage of $80 \mathrm{~V}$ for $0.5 \mathrm{~h}$ and $120 \mathrm{~V}$ for another $1.5 \mathrm{~h}$. The resolved proteins were electrophoretically transferred to polyvinylidine difluoride membranes (EMD Millipore, Bedford, MA, USA) and blocked with $5 \%$ skimmed milk for $2 \mathrm{~h}$. Subsequently,

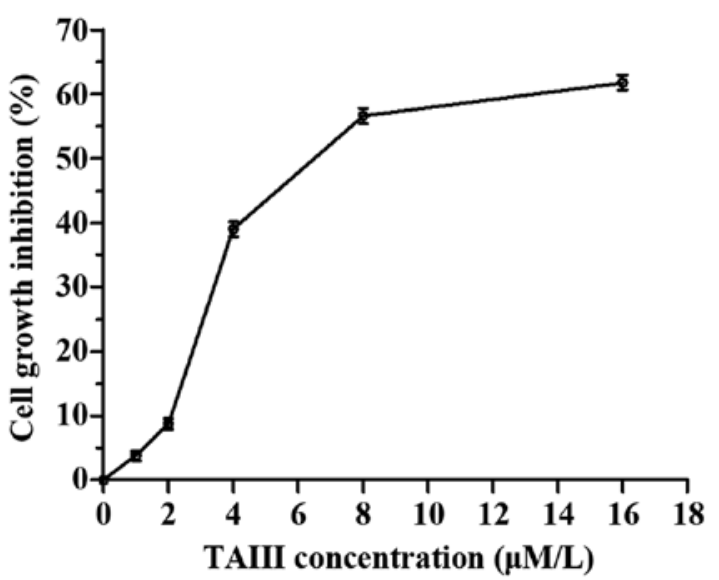

Figure 1. K562/ADM cells were treated with various concentrations of TAIII for $24 \mathrm{~h}$. Proliferation of K562/ADM cells was determined using CCK-8 assay, and the inhibition rate (\%) was calculated. The data are shown as mean $\pm \mathrm{SD}$ for three independent experiments. ${ }^{*} \mathrm{P}<0.05$.

the membranes were incubated overnight at $4^{\circ} \mathrm{C}$ with specific antibodies. The primary antibodies were rabbit polyclonal antibodies against P-gp (1:500), MRP-1 (1:500), total-Akt (1:500), p-Akt (1:500), GADPH (1:1,000). The following day, the membranes were incubated in horseradish peroxidase-labeled goat anti-rabbit immunoglobulin $\mathrm{G}(1: 5,000)$ for $2 \mathrm{~h}$ at room temperature. Finally, images were captured by a FluorChem FC2 gel imaging system (Alpha Innotech, San Leandro, CA, USA). The intensity of each band was normalized by GADPH for their respective lanes.

Data analysis. Statistical analyses were performed using SPSS17.0 software (IBM SPSS, Armonk, NY, USA). Data were expressed as the means \pm SD. Statistical comparisons were evaluated by one-way ANOVA. Values of $\mathrm{P}<0.05$ was considered statistically significant.

\section{Results}

Multi-drug resistance of K562/ADM cells. Compared with its parental cells, K562/ADM cells showed clear drug-resistant property. As shown in Table I, the $\mathrm{IC}_{50}$ of ADM on K562 and K562/ADM cells were 1.013 and $32.176 \mathrm{mg} / 1$, respectively. The drug-resistance was 31.78 -fold $(\mathrm{P}<0.05)$.

Direct cytotoxic activity of TAIII. TAIII inhibited viability of K562/ADM cells in a dose-dependent manner (Fig. 1). TAIII of $1 \mu \mathrm{M}$ had no significant cytotoxicity (cell growth inhibition $<5 \%$ ), and $2 \mu \mathrm{M}$ TAIII had a very weak cytotoxicity (cell growth inhibition $<10 \%$ ). To minimize TAIII itself on K562/ADM cells growth, 1 and $2 \mu \mathrm{M}$ was selected.

Reversal of drug resistance by TAIII. As shown in Fig. 2, the reversal effect of TAIII on K562/ADM cells was dosedependent. The $\mathrm{IC}_{50}$ values of $\mathrm{ADM}$ in $\mathrm{K} 562 / \mathrm{ADM}$ cells were $30.74 \pm 2.77,20.05 \pm 1.18$ and $12.19 \pm 2.17 \mathrm{mg} / \mathrm{l}$ for ADM plus vehicle, ADM plus $1 \mu \mathrm{M}$ TAIII and ADM plus $2 \mu \mathrm{M}$ TAIII, respectively. The reversal fold-change of TAIII of 1 and $2 \mu \mathrm{M}$ was 1.50 and 2.52 , respectively (Table II, $\mathrm{P}<0.05$ ). 


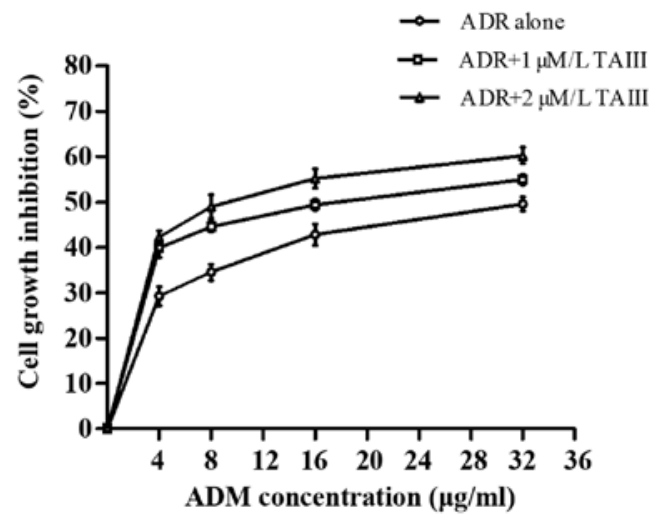

Figure 2. TAIII treatment altered ADM-induced cytotoxicity of K562/ADM cells. Growth curves are based on data from CCK-8 assays in K562/ADM cells after 24-h culture in the absence or presence of 1 and $2 \mu \mathrm{M}$ TAIII. The results showed increasing drug sensitivity in a dose-dependent manner in K562/ADM cells. Results are expressed as mean \pm SD for three independent experiments. ${ }^{*} \mathrm{P}<0.05$.
Effect of TAIII on the intracellular accumulation of ADM. The intracellular accumulation of ADM decreased significantly in K562/ADM cells compared to the parental K562 cells $(26,27)$. We determined that TAIII increased the intracellular accumulation of ADM in K562/ADM cells. Our results indicated that TAIII elevated the sensitivity of K562/ADM cells toward ADM through increasing intracellular ADM accumulation (Fig. 3A; $\mathrm{P}<0.05$ ). As show in Fig. 3D, the fluorescence intensity of ADM in TAIII-treated K562/ADM cells increased in a dose-dependent manner compared to untreated K562/ADM cells.

TAIII inhibits P-gp and MRP1-mediated transport. To assess the impact of TAIII treatment on the function of P-gp and MRP1 as efflux pump in K562/ADM cells, we examined the P-gp-mediated Rho-123 and MRP1-mediated CFDA transports in the cells treated with TAIII. As shown in Fig. 3B, Fig. 3C and D, TAIII treatment significantly increased the

A ADM
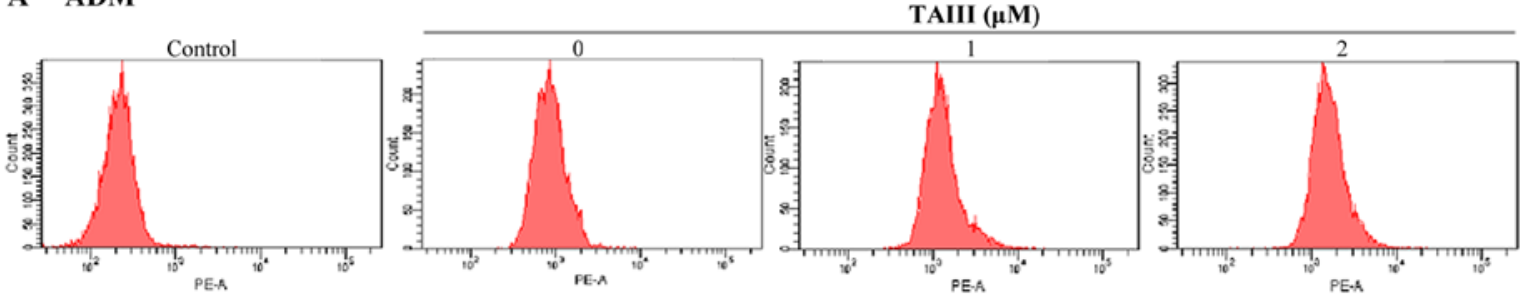

B Rho-123
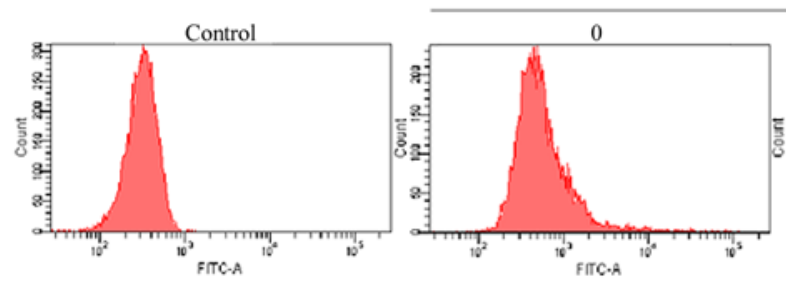

TAIII $(\mu \mathrm{M})$
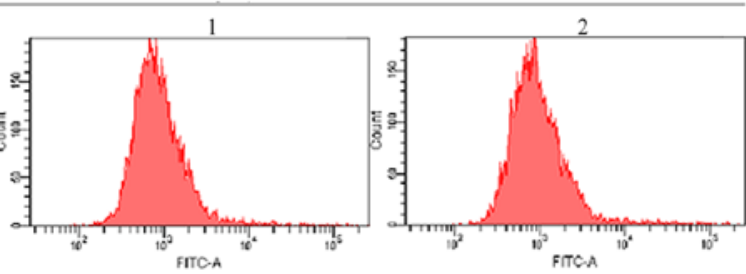

C CFDA
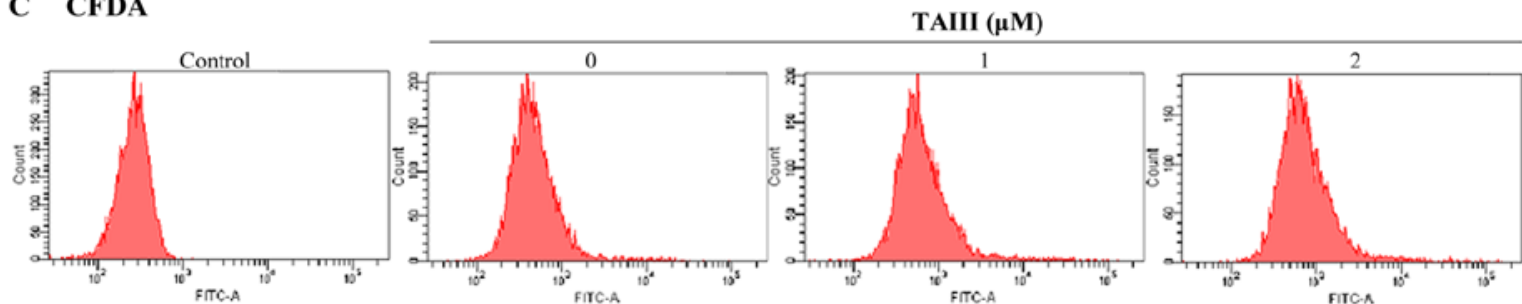

D MFI
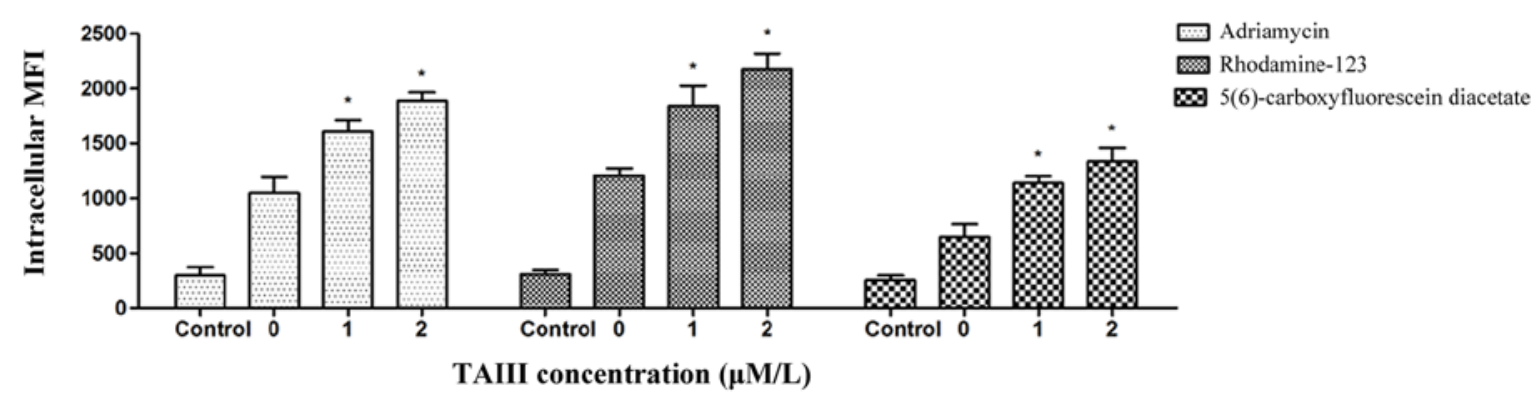

5(6)-carboxyfluorescein diacetate

TAIII concentration $(\mu \mathrm{M} / \mathrm{L})$

Figure 3. The effect of TAIII on the intracellular accumulation of adriamycin (ADM), rhodamine-123 (Rho-123) and 5(6)-carboxyfluorescein diacetate (CFDA) of K562/ADM cells. (A) TAIII significantly increased the ADM-associated MFI in K562/ADM cells in a dose-dependent manner. (B) Rho-123 was used as a special substrate for P-gp to test P-gp activity in K562/ADM cells. The FCM results showed that there was an increasing intracellular accumulation of Rho-123 in K562/ADM cells in a dose-dependent manner. (C) CFDA was used as a model MRP1 substrate to evaluate the function of MRP1. The FCM results showed that there was an increased intracellular accumulation of CFDA in K562/ADM cells. (D) Enhanced uptake of ADM, Rho-123 and CFDA presented in terms of mean fluorescence intensity value. Bars means $\pm \mathrm{SD}$. $\mathrm{n}=4$. $\mathrm{P}>0.05$, compared to the control group; ${ }^{*} \mathrm{P}<0.05$, compared to the control group. 
Table II. Effect of TAIII on the sensitivity of K562/ADM cells toward ADM by CCK- 8 assay (means \pm SD of triplicate experiments).

\begin{tabular}{lcc}
\hline Treament & $\mathrm{IC}_{50}(\mu \mathrm{g} / \mathrm{ml})$ & Reversal fold (RF) \\
\hline ADM alone & $30.743 \pm 2.7661$ & \\
ADM $+1 \mu \mathrm{M}$ TAIII & $20.524 \pm 1.1798^{\mathrm{a}}$ & 1.50 \\
ADM $+2 \mu \mathrm{M}$ TAIII & $12.192 \pm 2.1667^{\mathrm{a}}$ & 2.52 \\
\hline
\end{tabular}

${ }^{\mathrm{a}} \mathrm{P}<0.05$ vs. ADM alone.
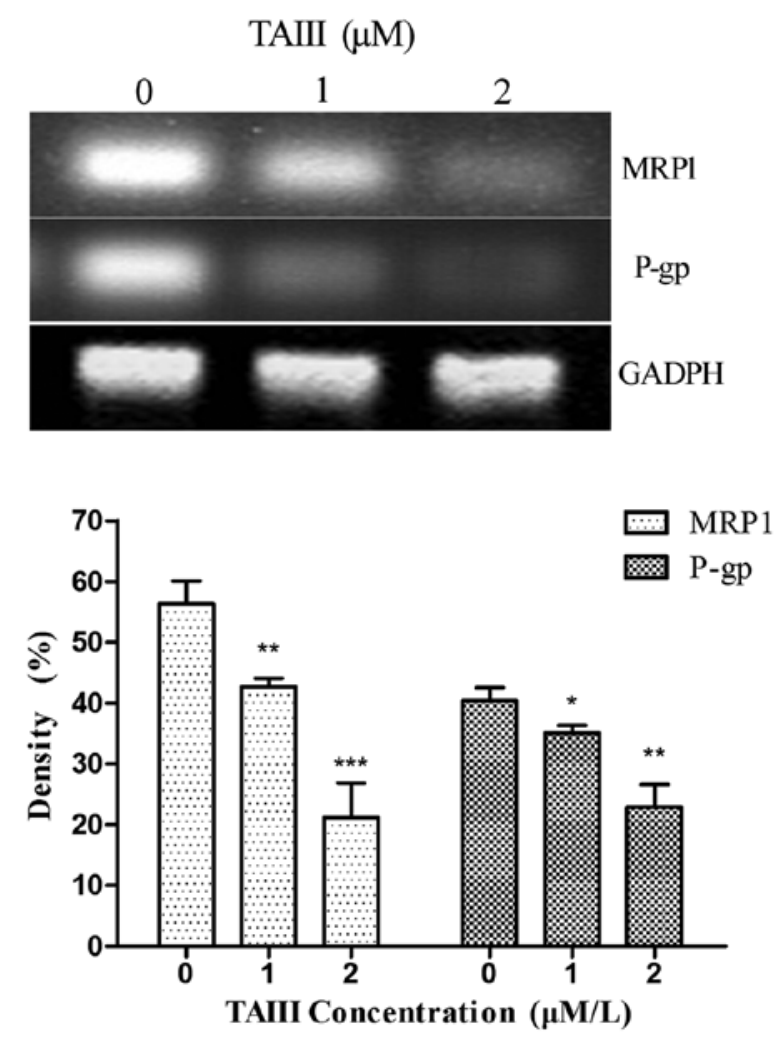

Figure 4. TAIII treatment decreases the expression of P-gp and MRP1 mRNA in K562/ADM cells in a dose-dependent manner. P-gp and MRP1 mRNA levels were evaluated after $24 \mathrm{~h}$ of 1 and $2 \mu \mathrm{M}$ TAIII treatment. Total RNA was isolated and used in RT-PCR to determine changes in P-gp and MRP1 mRNA levels after normalization to GADPH expression. The results are expressed as the mean \pm SD for three independent experiments. Bars means \pm SD. $n=3$. $\mathrm{P}>0.05$, compared to the control group; ${ }^{*} \mathrm{P}<0.05,{ }^{* *} \mathrm{P}<0.01$, ${ }^{* * *} \mathrm{P}<0.001$ versus control group.

intracellular accumulation of Rho-123 and CFDA in a dosedependent manner $(\mathrm{P}<0.05)$.

TAIII decreases expression of P-gp and MRP1 in K562/ADM cells via the PI3K/Akt signaling pathway. P-gp and MRP1 are $A B C$ transporters, which are overexpressed in many drug-resistant cells $(8,12,13)$. K562/ADM cells express higher levels of P-gp and MRP1 than K562 cells $(26,28)$. In this study, K562/ADM cells expressed P-gp and MRP1 protein at high level. After incubation alone or with TAIII $(1$ and $2 \mu \mathrm{M})$ for $24 \mathrm{~h}$, the expression levels of P-gp and MRP1 were determined
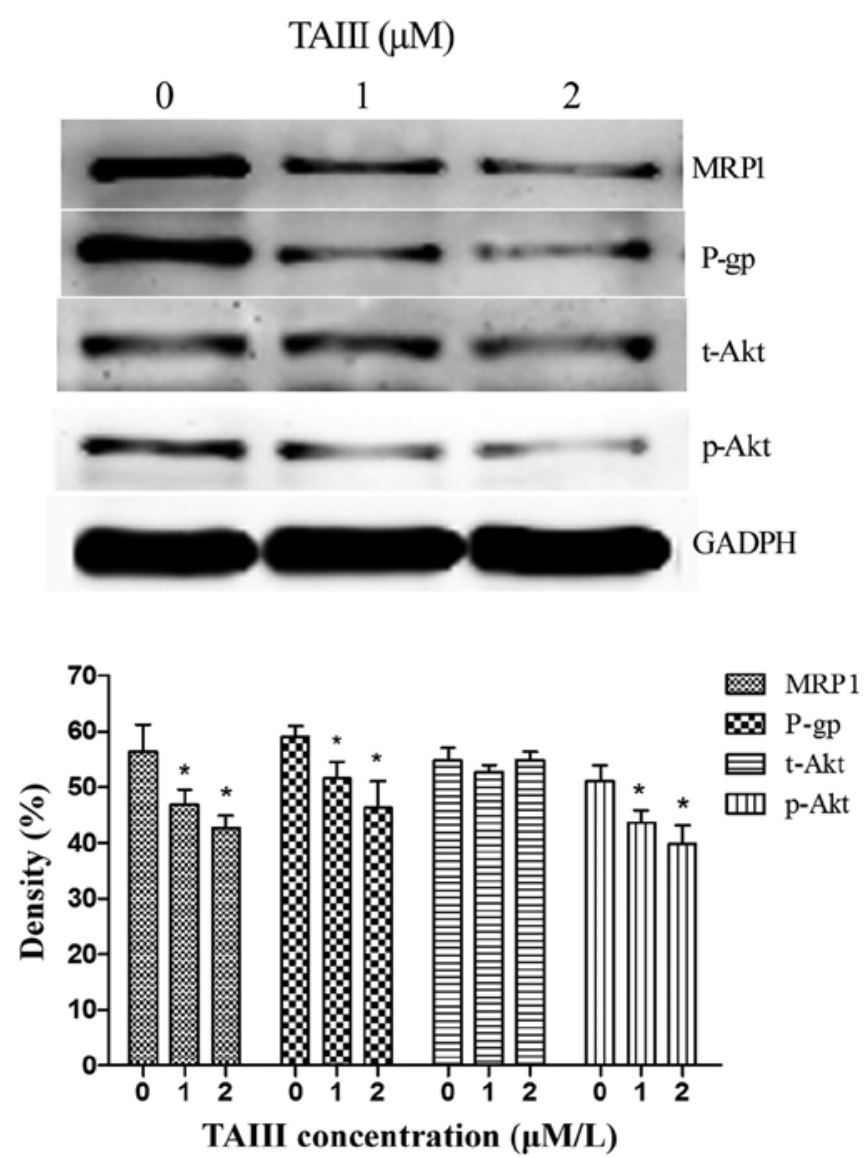

Figure 5. The effect of TAIII on expression of drug resistance related proteins in K562/ADM cells. After TAIII $(0,1$ and $2 \mu \mathrm{M})$ treatment for $24 \mathrm{~h}$, western blotting results showed decreased protein expression of P-gp, MRP1 and p-Akt in human CML K562/ADM cells. GADPH was the internal control. The results are expressed as the mean \pm SD for three independent experiments. Bars means \pm SD. $n=3$. $P>0.05$, compared to the control group; ${ }^{*} \mathrm{P}<0.05,{ }^{* *} \mathrm{P}<0.01$ compared to the control group.

by RT-PCR and western blotting (Figs. 4 and 5). The results of RT-PCR are shown in the Fig. 4, the MDR1 and MRP1 mRNA expression in K562/ADM cells significantly decreased in a dose-dependent manner $(\mathrm{P}<0.05)$. The results of western blotting are shown in Fig. 5, compared to the negative control group, TAIII was able to induce a significant downregulation of P-gp and MRP1 protein expression in a dose-dependent manner. These results indicated that TAIII could modulate P-gp and MRP1 gene expression, thus increasing the intracellular ADM accumulation.

PI3K/Akt signaling pathway played a vital role in the development of CML MDR, and was closely related to high expressions of P-gp and MRP1 $(2,4)$. In order to further analyze the inhibitory effects of TAIII on the expression of P-gp and MRP1, we analyzed the alteration of total expression and activity of Akt (Akt Ser473) in K562/ADM cells. Akt is one of the most important modulators in PI3K/Akt pathway. As shown in Fig. 5, after treatment with TAIII for $24 \mathrm{~h}$, the expression of total-Akt did not change apparently, whereas the expression of Akt phosphorylation (Akt Ser473) changed significantly $(\mathrm{P}<0.05$, Fig. 5). These data suggested that the $\mathrm{PI} 3 \mathrm{~K} / \mathrm{Akt}$ pathway is involved in the TAIII mediated reversal of multidrug resistance of K562/ADM cells. 

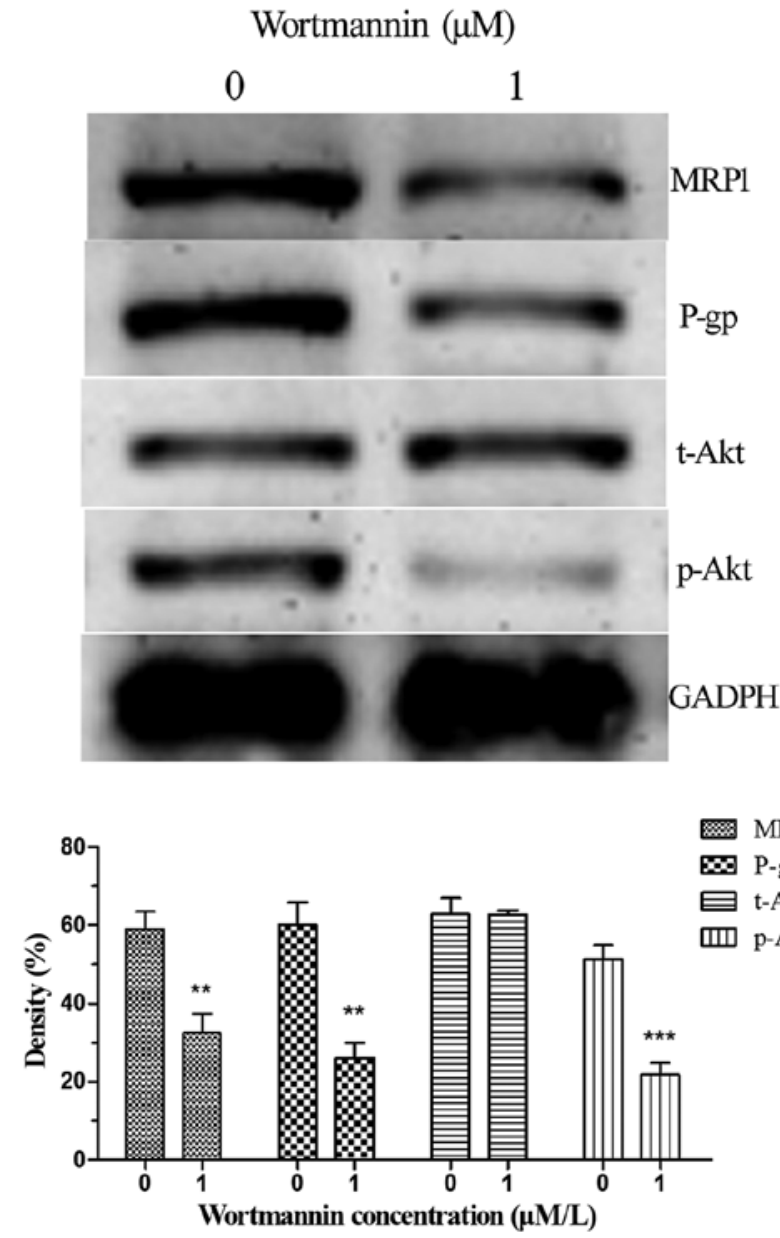

Figure 6. Effect of PI3K/Akt signaling pathway inhibitor on drug resistance related protein expression in K562/ADM cells. Cells were pretreated with or without PI3K/Akt inhibitor wortmannin $(1 \mu \mathrm{M})$ for $24 \mathrm{~h}$, and then the relative expression level of $\mathrm{p}$-Akt, P-gp and MRP1 was measured by western blotting. The downregulated expression of p-Akt, P-gp and MRP1 was calculated after normalization to GADPH expression. Bars means \pm SD. $n=3$. P $>0.05$, compared to the control group; ${ }^{*} \mathrm{P}<0.05,{ }^{* * *} \mathrm{P}<0.01,{ }^{* * *} \mathrm{P}<0.001$ compared to the control group.

Blocking PI3K/Akt pathway modulates the chemosensitivity of K562/ADM cells. To further determine the causal relationship between chemosensitivity and TAIII-inactivated PI3K/ Akt signaling pathway on cell MDR, specific inhibitor of $\mathrm{PI} 3 \mathrm{~K} / \mathrm{Akt}$ wortmannin was selected to treat K562/ADM cells which overexpressed P-gp and MRP1. The protein levels of total-Akt, Akt Ser473, P-gp and MRP1 were measured. As shown in Fig. 6, K562/ADM cells with the inhibitor wortmannin treatment showed significantly decreasing protein levels of Akt Ser473, P-gp and MRP1, whereas total Akt was not affected by inhibition $(\mathrm{P}<0.05)$.

The inhibition of PI3K/Akt pathway plays a crucial role in the multidrug-resistance reversal of TAIII. In order to confirm the role of PI3K/Akt signaling pathway in TAIII-mediated reversal effect of multidrug resistance, we analyzed the proteins level of total-Akt, Akt Ser473, P-gp and MRP1 in K562/ADM cells by western blotting. The cells were treated with wortmannin $(1 \mu \mathrm{M})$ alone and combined-treatment with TAIII (1 and $2 \mu \mathrm{M})$ for $24 \mathrm{~h}$. The results of western blotting are shown in Fig. 7,

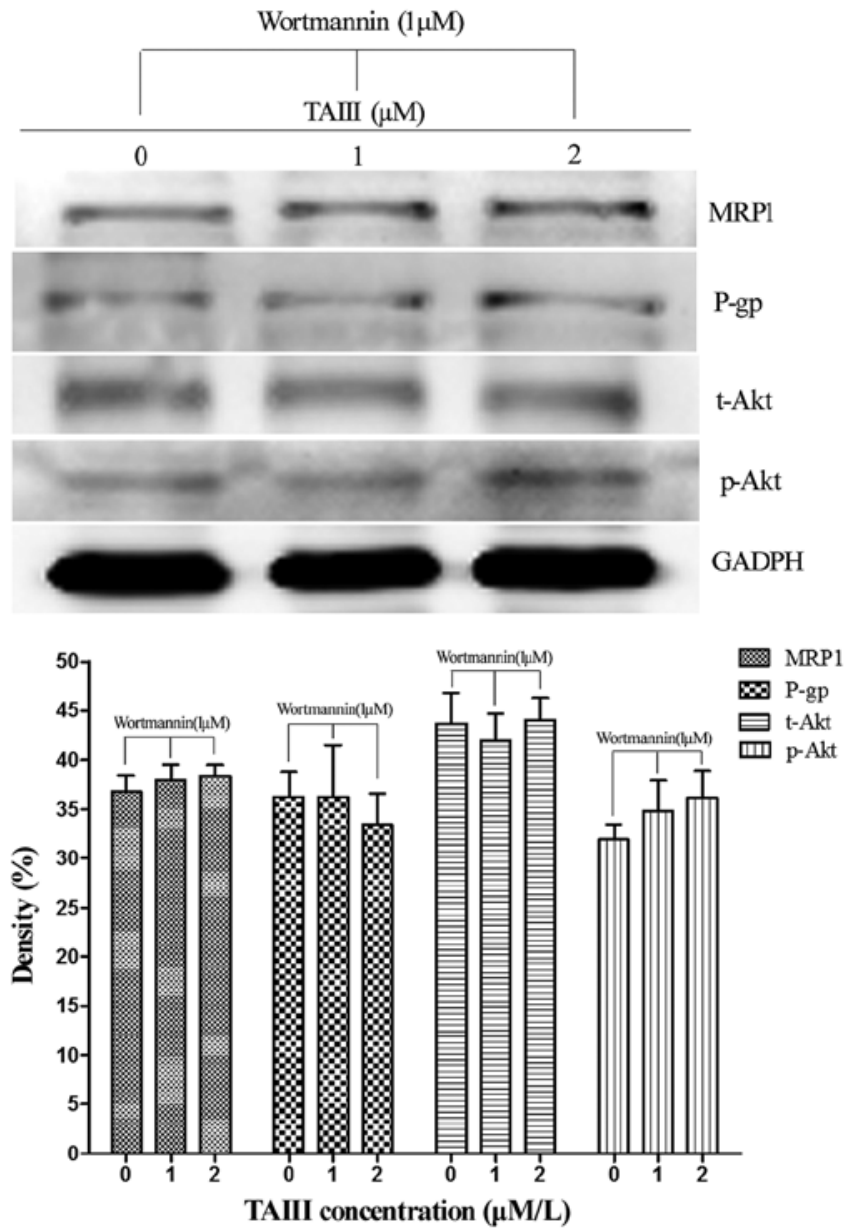

Figure 7. The effect of wortmannin $(1 \mu \mathrm{M})$ combined-treatment with TAIII (1 and $2 \mu \mathrm{M}$ ) on expression of drug resistance related proteins in K562/ADM cells. Cells were treated with wortmannin $(1 \mu \mathrm{M})$ alone and combined-treatment with TAIII $(1$ and $2 \mu \mathrm{M})$ for $24 \mathrm{~h}$ and then the relative expression level of p-Akt, P-gp and MRP1 were measured by western blotting. The effects of wortmannin in inhibiting of the level of p-Akt, P-gp and MRP1 did not change significantly after treatment with TAIII in K562/ADM cells. Bars means \pm SD. $n=3$. $P>0.05$, compared to the control group.

compared with wortmannin $(1 \mu \mathrm{M})$ alone group, wortmannin $(1 \mu \mathrm{M})$ combined with TAIII $(1 \mu \mathrm{M})$ group and wortmannin $(1 \mu \mathrm{M})$ combined with TAIII $(2 \mu \mathrm{M})$ group did not attenuate the expression of p-Akt, P-gp and MRP1. Since TAIII did not strengthen the inhibitor function, we may conclude that PI3K/ Akt signaling pathway was mainly responsible for the drug resistance reversal effect of TAIII.

\section{Discussion}

CML is one of the most genetically homogeneous malignancies characterized by clonal myeloid cells with an abnormal fusion protein, BCR-ABL, which has tyrosine kinase activity. Since biological sample collection is a non-invasive process, CML is one of the extensively studied diseases for gene expression profiling, which needs elucidation of the BCR-ABL downstream mechanisms involved in CML progression and the pathways involved in therapy resistance. Although the BCR-ABL-targeting tyrosine kinase inhibitors (TKIs) has shown significant progress toward treatment against CML, the 
drug did not successfully cure patients of the disease $(9,29)$. MDR has become a main obstacle for chemotherapy of CML. Mechanism of MDR is associated with altered expression of ATP-binding cassette (ABC) family of transporters on cell membrane, the most common cause of multidrug resistance (MDR) (1). While as many as 18 ABC transporters have been observed to export chemotherapy drugs using in vitro experimental systems, only 3 transporters have been implicated as major contributors to MDR in cancer: P-glycoprotein (Pgp; ABCB1; MDR1), multidrug resistance-associated protein (MRP1; ABCC1) and breast cancer resistance protein (BCRP; ABCG) (30). Moreover, among the three transporters, the expression of P-gp and MRP1 was extensively measured, studied in CML and its expression levels were correlated with multidrug resistance (31).

The PI3K/Akt signaling pathway has become an important player in the pathogenesis of MDR CML and a promising target for systemic therapy $(1,2,4,5,9-11)$. Many cancer cells have mutations in the PI3K/Akt pathway that leads to hyperactivation of this pathway. In previous studies, it was reported that the PI3K/Akt signaling pathway was always prominently activated by many regulators and was strongly linked to prosurvival in cancer cells (9). Moreover, several lines of evidence implicated that the activating of PI3K/Akt signaling pathway had enhanced drug efflux by ATP-binding cassette (ABC) transporters (2). The maintaining of MDR in tumor cells by PI3K/Akt signaling pathway was most correlated with P-gp and MRP1 (4). Blocking the PI3K/Akt signaling pathway results in the downregulation of the expression of $\mathrm{P}$-gp and MRP1, the sensitivity to chemotherapy drugs was regained (4).

TAIII, one of the main active constituents of Chinese medicinal herb Anemarrhena asphodeloides Bunge, was reported to possess a variety of pharmacological functions. There is accumulating evidence that TAIII is a pronounced activator of autophagy $(21,32,33)$. Preclinical study reported that TAIII was efficacious in inducing autophagy in various cancer cells correlating with a potent inhibitory effect on the activity of mammalian target of rapamycin (mTOR) (31-33). Moreover, it has been reported that the PI3K/Akt/mTOR signaling pathway played a suppressive role in autophagy (10). Furthermore, TAIII can also induce tumor cells apoptosis by inhibition of mTORC1 (34). Nuclear factor-kappa B (NF- $\kappa$ B) is a transcription factor universally present in eukaryocytes, and it can enter into the nucleus and bind to some specific $\kappa \mathrm{B}$ sequences thus inducing or upregulating expression of certain genes (27). Previous studies demonstrated that $\mathrm{NF}-\kappa \mathrm{B}$ could bind to the specific $\kappa \mathrm{B}$ sequences on the first exon of the MDR1 promoter region and then upregulated the expression of P-gp to induce drug resistance $(27,35)$. Studies have shown that TAIII has strong anti-inflammatory properties by inhibiting the expression of inflammatory cytokines via inhibition of $N F-\kappa B$ activation $(16,17)$. However, $N F-\kappa B$ was also reported as a downstream signal molecule of PI3K/Akt signaling pathway $(36,37)$. Based on these studies, it is possible to conclude that TAIII may have an inhibition effect on PI3K/ Akt signaling pathway.

In this study, we investigated the effects of MDR reversal in a CML multidrug-resistant cell line K562/ADM using TAIII. Firstly, we determined the non-toxic concentration of TAIII to reverse drug-resistance. We found that TAIII of 1 and $2 \mu \mathrm{M}$ showed very weak cytotoxcity (cell growth inhibition $<10 \%$ ). Then, our data demonstrated that TAIII and ADM combined treatment sensitized K562/ADM cells and induced apoptosis in a dose-dependent manner, decreasing P-gp and MRP1 gene expression. Additionally, the combined treatment reduced the expression of phosphorylated Akt (p-Akt) without affecting the expression of total-Akt, that means the activity of PI3K/ Akt signaling pathway was downregulated. Moreover, we found that the levels of p-Akt, P-gp and MRP1 in K562/ADM cells decreased after exposure to the specific inhibitor of PI3K/ Akt wortmannin. However, TAIII treatment combined with wortmannin did not exhibit strengthen effect on downregulation of P-gp and MRP1 expression. Therefore, it is reasonable to believe that TAIII plays a suppressive role in the expression of P-gp and MRP1 via inhibition of the PI3K/Akt signaling pathway.

The above studies show that TAIII could increase the intracellular accumulation of ADM in K562/ADM cells at non-toxic concentrations by downregulating P-gp and MRP1 expressions, function and transcription via a mechanism involving the inhibition of the PI3K/Akt signaling pathway. The studies provide evidence in support of further investigation into the clinical application of TAIII as new, potent, and clinically relevant MDR reversal agent in cancer chemotherapy.

\section{Acknowledgements}

This study was supported by the Shandong Science and Technology Committee (no. 2010GSF10264), the Foundation of Shandong Educational Committee (nos. J10LC60 and J11LC01), Natural Science Foundation of Shandong Province (no. ZR2014HL032) and Projects of Medical and Health Technology Development Program in Shandong province (no. 2014WS0183).

\section{References}

1. Rodrigues AS, Dinis J, Gromicho M, Martins C, Laires A and Rueff J: Genomics and cancer drug resistance. Curr Pharm Biotechnol 13: 651-673, 2012.

2. Zhang X, Dong W, Zhou H, Li H, Wang N, Miao X and Jia L: a-2, 8-Sialyltransferase is involved in the development of multidrug resistance via PI3K/Akt pathway in human chronic myeloid leukemia. IUBMB Life 67: 77-87, 2015.

3. Kalle AM, Sachchidanand S and Pallu R: Bcr-Abl-independent mechanism of resistance to imatinib in K562 cells: Induction of cyclooxygenase-2 (COX-2) by histone deacetylases (HDACs). Leuk Res 34: 1132-1138, 2010.

4. Ma H, Cheng L, Hao K, Li Y, Song X, Zhou H and Jia L: Reversal effect of ST6GAL 1 on multidrug resistance in human leukemia by regulating the PI3K/Akt pathway and the expression of P-gp and MRP1. PLoS One 9: e85113, 2014.

5. Cheng Z, Yang N, Liang W, Yan X, Li L and Pan L: Effect of PTEN gene transfection on the reversal of multidrug resistance in K562/ADM cells. Leuk Lymphoma 53: 1383-1389, 2012.

6. Dharmapuri G, Doneti R, Philip GH and Kalle AM: Celecoxib sensitizes imatinib-resistant K562 cells to imatinib by inhibiting MRP1-5, ABCA2 and ABCG2 transporters via Wnt and Ras signaling pathways. Leuk Res 39: 696-701, 2015.

7. Kang Q and Yan S: Piperlongumine reverses doxorubicin resistance through the PI3K/Akt signaling pathway in K562/A02 human leukemia cells. Exp Ther Med 9: 1345-1350, 2015.

8. Zhang Z, Xu K, Bi Y, Yu G, Wang S, Qi X and Zhong H: Low intensity ultrasound promotes the sensitivity of rat brain glioma to doxorubicin by downregulating the expressions of P-glucoprotein and multidrug resistance protein 1 in vitro and in vivo. PLoS One 8: e70685, 2013. 
9. Barrett D, Brown VI, Grupp SA and Teachey DT: Targeting the $\mathrm{PI} 3 \mathrm{~K} / \mathrm{AKT} / \mathrm{mTOR}$ signaling axis in children with hematologic malignancies. Paediatr Drugs 14: 299-316, 2012.

10. Sheng Z, Ma L, Sun JE, Zhu LJ and Green MR: BCR-ABL suppresses autophagy through ATF5-mediated regulation of mTOR transcription. Blood 118: 2840-2848, 2011.

11. Li Q, Wu Y, Fang S, Wang L, Qi H, Zhang Y, Zhang J and Li W: $\mathrm{BCR} / \mathrm{ABL}$ oncogene-induced PI3K signaling pathway leads to chronic myeloid leukemia pathogenesis by impairing immunomodulatory function of hemangioblasts. Cancer Gene Ther 22: 227-237, 2015.

12. Wang Z, Yang L, Xia Y, Guo C and Kong L: Icariin enhances cytotoxicity of doxorubicin in human multidrug-resistant osteosarcoma cells by inhibition of $\mathrm{ABCB} 1$ and down-regulation of the PI3K/Akt pathway. Biol Pharm Bull 38: 277-284, 2015.

13. Xie X, Tang B, Zhou J, Gao Q and Zhang P: Inhibition of the PI3K/Akt pathway increases the chemosensitivity of gastric cancer to vincristine. Oncol Rep 30: 773-782, 2013.

14. Tsou SH, Chen TM, Hsiao HT and Chen YH: A critical dose of doxorubicin is required to alter the gene expression profiles in MCF-7 cells acquiring multidrug resistance. PLoS One 10: e0116747, 2015.

15. Cheng L, Luo S, Jin C, Ma H, Zhou H and Jia L: FUT family mediates the multidrug resistance of human hepatocellular carcinoma via the PI3K/Akt signaling pathway. Cell Death Dis 4: e923, 2013.

16. Lee B, Jung K and Kim DH: Timosaponin AIII, a saponin isolated from Anemarrhena asphodeloides, ameliorates learning and memory deficits in mice. Pharmacol Biochem Behav 93: $121-127,2009$

17. Lim SM, Jeong JJ, Kang GD, Kim KA, Choi HS and Kim DH: Timosaponin AIII and its metabolite sarsasapogenin ameliorate colitis in mice by inhibiting NF- $\mathrm{KB}$ and MAPK activation and restoring Th17/Treg cell balance. Int Immunopharmacol 25: 493-503, 2015.

18. Lee B, Trinh HT, Jung K, Han SJ and Kim DH: Inhibitory effects of steroidal timosaponins isolated from the rhizomes of Anemarrhena asphodeloides against passive cutaneous anaphylaxis reaction and pruritus. Immunopharmacol Immunotoxicol 32: $357-363,2010$

19. Kimura M, Kimura I and Chem FJ: Combined potentiating effect of byakko-ka-ninjin-to, its constituents, rhizomes of Anemarrhena asphodeloitles, timosaponin A-III, and calcium on pilocarpine-induced saliya secretion in streptozocin-diabetic mice. Biol Pharm Bull 19: 926-931, 1996.

20. Tang YH, Sun ZL, Fan MS, Li ZX and Huang CG: Anti-diabetic effects of TongGuanWan, a Chinese traditional herbal formula in C57BL/KsJ-db/db mice. Planta Med 78: 18-23, 2012

21. Lok CN, Sy LK, Liu F and Che CM: Activation of autophagy of aggregation-prone ubiquitinated proteins by timosaponin A-III. J Biol Chem 286: 31684-31696, 2011.

22. Kang YJ, Chung HJ, Nam JW, Park HJ, Seo EK, Kim YS, Lee D and Lee SK: Cytotoxic and antineoplastic activity of timosaponin A-III for human colon cancer cells. J Nat Prod 74: 701-706, 2011.

23. Wang YZ, Feng B, Huang HZ, Kang LP, Cong Y, Zhou WB Zou P, Cong YW, Song XB and Ma BP: Glucosylation of steroidal saponins by cyclodextrin glucanotransferase. Planta Med 76: 1724-1731, 2010 .
24. Huang HL, Chiang WL, Hsiao PC, Chien MH, Chen HY, Weng WC, Hsieh MJ and Yang SF: Timosaponin AIII mediates caspase activation and induces apoptosis through JNK1/2 pathway in human promyelocytic leukemia cells. Tumour Biol 36: 3489-3497, 2015.

25. Wang S, Wang S, Wang C, Chen Y, Li J, Wang X, Wang D, Li Z, Peng Z and Fan L: Upregulation of multidrug resistanceassociated protein 1 by Allyl isothiocyanate in human bronchial epithelial cell: Involvement of c-Jun N-terminal kinase signaling pathway. Oxid Med Cell 2015: 903782, 2015.

26. Wang L, Meng Q, Wang C, Liu Q, Peng J, Huo X, Sun H, Ma X and Liu K: Dioscin restores the activity of the anticancer agent adriamycin in multidrug-resistant human leukemia K562/adriamycin cells by down-regulating MDR1 via a mechanism involving NF- $\kappa B$ signaling inhibition. J Nat Prod 76: 909-914, 2013.

27. Wang H, Wang X, Li Y, Liao A, Fu B, Pan H, Liu Z and Yang W: The proteasome inhibitor bortezomib reverses P-glycoproteinmediated leukemia multi-drug resistance through the NF-B pathway. Pharmazie 67: 187-192, 2012.

28. Xu X, Zhang Y, Li W, Miao H, Zhang H, Zhou Y, Li Z, You Q, Zhao L and Guo Q: Wogonin reverses multi-drug resistance of human myelogenous leukemia K562/A02 cells via downregulation of MRP1 expression by inhibiting Nrf2/ARE signaling pathway. Biochem Pharmacol 92: 220-234, 2014.

29. Sinclair A, Latif AL and Holyoake TL: Targeting survival pathways in chronic myeloid leukaemia stem cells. Br J Pharmacol 169: 1693-1707, 2013.

30. Lage H: An overview of cancer multidrug resistance: A still unsolved problem. Cell Mol Life Sci 65: 3145-3167, 2008.

31. Vasconcelos FC, Silva KL, Souza PS, Silva LF, MoellmannCoelho A, Klumb CE and Maia RC: Variation of MDR proteins expression and activity levels according to clinical status and evolution of CML patients. Cytometry B Clin Cytom 80B: 158-166, 2011.

32. Sy LK, Yan SC, Lok CN, Man RY and Che CM: Timosaponin A-III induces autophagy preceding mitochondria-mediated apoptosis in HeLa cancer cells. Cancer Res 68: 10229-10237, 2008.

33. Wang N, Feng Y, Zhu M, Siu FM, Ng KM and Che CM: A novel mechanism of XIAP degradation induced by timosaponin AIII in hepatocellular carcinoma. Biochim Biophys Acta 1833: 2890-2899, 2013

34. King FW, Fong S, Griffin C, Shoemaker M, Staub R, Zhang YL, Cohen I and Shtivelman E: Timosaponin AIII is preferentially cytotoxic to tumor cells through inhibition of mTOR and induction of ER stress. PLoS One 4: e7283, 2009.

35. Gao F, Liu J, Dong WW, Wang W, Wang Y, Cai D, Zheng Z and Sun K: Investigation of the mechanism involved in the $\mathrm{As}_{2} \mathrm{O}_{3-}$ regulated decrease in MDR1 expression in leukemia cells. Oncol Rep 31: 926-932, 2014.

36. Wang R, Shao F, Liu Z, Zhang J, Wang S, Liu J, Liu H, Chen H, Liu K, Xia M, et al: The Hsp90 inhibitor SNX-2112, induces apoptosis in multidrug resistant K562/ADR cells through suppression of $\mathrm{Akt} / \mathrm{NF}-\kappa \mathrm{B}$ and disruption of mitochondriadependent pathways. Chem Biol Interact 205: 1-10, 2013.

37. Zhu X, Wang L, Zhang B, Li J, Dou X and Zhao RC: TGF-beta1induced PI3K/Akt/NF-kappaB/MMP9 signalling pathway is activated in Philadelphia chromosome-positive chronic myeloid leukaemia hemangioblasts. J Biochem 149: 405-414, 2011. 